\title{
Effect of fat replacement by inulin or lupin-kernel fibre on sausage patty acceptability, post-meal perceptions of satiety and food intake in men†
}

\author{
Bridie J. Archer, Stuart K. Johnson*, Helen M. Devereux and Amynta L. Baxter \\ School of Health Sciences, Faculty of Health and Behavioural Science, Deakin University, 221 Burwood Hwy, \\ Burwood, Victoria, 3125, Australia
}

(Received 22 June 2003 - Revised 4 December 2003 - Accepted 17 December 2003)

\begin{abstract}
The present study examined whether replacing fat with inulin or lupin-kernel fibre influenced palatability, perceptions of satiety, and food intake in thirty-three healthy men (mean age 52 years, BMI $27.4 \mathrm{~kg} / \mathrm{m}^{2}$ ), using a within-subject design. On separate occasions, after fasting overnight, the participants consumed a breakfast consisting primarily of either a full-fat sausage patty (FFP) or a reduced-fat patty containing inulin (INP) or lupin-kernel fibre (LKP). Breakfast variants were alike in mass, protein and carbohydrate content; however the INP and LKP breakfasts were 36 and $37 \%$ lower in fat and 15 and $17 \%$ lower in energy density respectively compared with the FFP breakfast. The participants rated their satiety before breakfast then evaluated patty acceptability. Satiety was rated immediately after consuming the breakfast, then over the subsequent $4.5 \mathrm{~h}$ whilst fasting. Food consumed until the end of the following day was recorded. All patties were rated above 'neither acceptable or unacceptable', however the INP rated lower for general acceptability $(P=0.039)$ and the LKP lower for flavour $(P=0.023)$ than the FFP. The LKP breakfast rated more satiating than the INP $(P=0 \cdot 010)$ and FFP $(P=0 \cdot 016)$ breakfasts. Total fat intake was $18 \mathrm{~g}$ lower on the day of the INP $(P=0.035)$ and $26 \mathrm{~g}$ lower on the day of the LKP breakfast $(P=0.013)$ than the FFP breakfast day. Energy intake was lower $(1521 \mathrm{~kJ})$ only on the day of the INP breakfast $(P=0.039)$. Both inulin and lupin-kernel fibre appear to have potential as fat replacers in meat products and for reducing fat and energy intake in men.
\end{abstract}

Satiety: Fat replacers: Inulin: Lupin: Dietary fibre

There has been an increase in the availability of fatreduced foods in the past decade, a trend that in part appears driven by dietary guidelines that recommend reduced fat intake and a consumer desire for weight loss. Whilst there is debate over the role of fat in the development of obesity (Astrup et al. 1997; Willet 1998b), it would appear that weight loss or preventing weight gain can be accomplished by decreasing the fat content of the diet (Bray \& Popkin, 1998; Astrup et al. 2000) whilst simultaneously decreasing dietary energy density (Willet 1998a).

The satiating power of foods, that is their inhibitory effect on appetite preventing the next eating bout from commencing (Blundell \& Rogers, 1991), has recently been recognised by health professionals as an important factor to consider when planning low-energy weight-loss dietary regimens targeted at decreasing ad libitum energy intake (Tremblay et al. 2002). Evidence suggests that high-energy-dense foods, that is those typically high in fat and low in water and dietary fibre, are not considered highly satiating joule for joule (Holt et al. 1995). In addition, macronutrients per se have different effects on satiation and satiety, fat having a weaker impact, joule for joule, than protein, and carbohydrate. However, these differences appear to be negated when energy density is controlled (Rolls et al. 1988, 1994; Blundell et al. 1993; Raben et al. 2003). Nevertheless, when human volunteers are offered fat-rich, energy-dense foods they consume significantly more energy than when they are presented with low-energy-dense, carbohydrate-rich foods (Drewnowski, 1998).

Palatability has been identified as an important factor influencing food choice (Glanz et al. 1998) and voluntary consumption of highly palatable foods tends to be greater than that of foods with lower palatability (Yeomans et al. 1997). Therefore it is important to ensure that highly satiating, low-energy-dense, fat-reduced foods are also palatable to ensure long-term compliance to weight-loss diets utilising these foods. Unfortunately, it has been reported that the satiating power of food products is inversely related to their palatability (Holt et al. 1995), highlighting the need for innovative product development to overcome

\footnotetext{
Abbreviations: df, degrees of freedom; FFP, full-fat sausage patty; INP, inulin sausage patty; LKP, lupin-kernel-fibre sausage patty.

$\dagger$ Part of the data in the present paper was presented at the Australian Institute of Food Science and Technology Annual Convention, Adelaide, Australia, 1-4 July 2001.

* Corresponding author: Dr S. K. Johnson, fax +61392446017, email stukj@ deakin.edu.au
} 
this barrier. One product development approach is to use low-energy fat replacers in foods in order to reduce the energy density of the diet whilst maintaining high palatability, resulting in low-fat diets that should be more effective in the treatment of obesity (Astrup et al. 1997). The use of certain plant-derived non-digestible carbohydrates has potential for the replacement of fat in foods whilst maintaining some or all of the desirable technological and sensory-quality attributes of the original full-fat product. High-fat foods that are commonly consumed items in the diet, such as meat products (Walker et al. 1997), are ideal fat-replacement targets. Nevertheless, little information is available in the literature on the satiating power of foods in which fat is replaced by these non-digestible carbohydrates.

A non-digestible carbohydrate food ingredient that currently has commercial applications as a fat replacer is inulin. Inulin, a plant-derived fructose polymer that is undigested in the human upper gastrointestinal tract (Niness, 1999), is considered to fit within the current concept of the 'dietary fibre complex' (Cherbut, 2002). Chicory roots are commonly used for the commercial manufacture of inulin to form a white, odourless powder with very little sweetness (Franck, 2002). Inulin has useful fat-like properties that allow it to function technologically as a fat replacer often without compromising taste and texture (Devereux et al. 2003), whilst reducing the energy content of the food (Franck, 2002). Lupin-kernel fibre is a novel insoluble non-digestible carbohydrate that may have potential as a fat replacer. Lupin-kernel fibre is manufactured from the dehulled seeds of Australian sweet lupin (Lupinus angustifolius) after extraction of the protein, lipid and soluble carbohydrate fractions (Johnson \& Gray, 1993). This fibre, in the form of a pale coloured powder, with a bland flavour, has been used to boost the dietary fibre content of baked goods whilst maintaining high levels of consumer acceptability (Clark \& Johnson, 2002). Lupin-kernel fibre demonstrates unusually high water-binding and viscosity properties compared with other insoluble dietary fibres (CM Turnbull, AL Baxter and SK Johnson, unpublished results), indicating that it may have potential as a low-energy bulking agent and fat replacer in foods.

The present study examined the effect of replacing approximately one half of the fat in a sausage patty with inulin or lupin-kernel fibre on the sensory acceptability of the products, post-meal perceptions of satiety and daily energy and fat intakes of healthy men. The present study provided an opportunity to predict whether the use of inulin or lupin-kernel fibre as fat replacers could lead to reduced long-term energy intake and hence assist in the prevention and control of obesity.

\section{Methods}

\section{Study design}

The study was a within-subject design. Three meal challenges were presented over a period of 3 weeks. The challenges involved consumption, after an overnight fast, of three different test breakfasts on three separate mornings, $7 \mathrm{~d}$ apart. The three different test breakfasts incorporated either a conventional full-fat sausage patty (FFP), a patty in which inulin replaced around one half of the fat (inulin sausage patty; INP) or a patty in which lupinkernel fibre replaced around one half of the fat (lupinkernel-fibre sausage patty; LKP). The participants were not informed of the identity of the breakfasts, which were labelled with random three-digit codes and presented in a randomised order to counterbalance any order-of-treatment effect. After an overnight fast, the participants rated their perception of the palatability of the sausage patty, perceptions of satiety before and after consumption of the test breakfasts and recorded food consumption on the remainder of the test day and the following day.

\section{Participants}

Thirty-three male participants' mean age 52 (SD 8, range 37-64) years were recruited from university staff and students and via advertisements in local newspapers. Their mean BMI was 27.4 (SD $4 \cdot 1$, range $20 \cdot 5-38 \cdot 7$ ) $\mathrm{kg} / \mathrm{m}^{2}$. The participants were untrained in sensory evaluation, were regular breakfast eaters, did not report allergies or sensitivities to common foods, had no history of gastrointestinal problems, were non-smokers, and were not taking any medication that might affect appetite.

\section{Sausage patty reformulation}

A full-fat conventional sausage patty and two reduced-fat sausage patty formulations using either inulin or lupinkernel fibre were developed (Table 1). In the reduced-fat

Table 1. Formulation of sausage patties used in test breakfasts $(\mathrm{g})$

\begin{tabular}{lccc}
\hline & Full-fat patty & Inulin patty & Lupin-kernel-fibre patty \\
\hline Beef mince* $^{*}$ & 500 & 500 & 500 \\
Sausage pre-mix $†$ & 60 & 60 & 60 \\
Beef dripping $\ddagger$ & 100 & 0 & 0 \\
Inulin§ & 0 & 24 & 0 \\
Lupin kernel fibre & 0 & 0 & 24 \\
Water & 150 & 226 & 226 \\
\hline
\end{tabular}

* Premium grade (Coles Supermarket, Donvale, VIC, Australia)

† 1002 Cambridge S/M (Corona Manufacturing Pty Ltd, Knoxfield, VIC, Australia).

$\ddagger$ Wik Industries Pty Ltd, Laverton North, VIC, Australia.

§Orafti Raftline HP (Mandurah Australia Pty Ltd, Dandenong, VIC, Australia).

\| Australasian Natural Ingredients Pty Ltd, Perth, WA, Australia. 
formulations, inulin or lupin-kernel fibre along with additional water with a total mass of $100 \mathrm{~g}$ was used to replace the $100 \mathrm{~g}$ beef dripping. The amount of water required for hydration and level of replacement of fat was based on the manufacturer's recommendations for the use of inulin in fat-reduced frankfurters (Orafti, 1997). Sausage patties were manufactured by manually combining the mince and the dripping (along with inulin or lupin-kernel fibre in the reduced-fat formulations). The sausage premix was then added along with the water and manually combined. Using a food processor, the mixture was blended until a smooth paste was obtained and $120 \mathrm{~g}$ portions of the raw mixture were baked at $220^{\circ} \mathrm{C}$ for $15 \mathrm{~min}$ in a Westinghouse Aquaria convection oven (Email Ltd, Dandenong, VIC, Australia). To reduce batch-to-batch variation in formulation and ingredients, all patties for each participant were pre-prepared at the same time from a single batch of ingredients and stored at $-18^{\circ} \mathrm{C}$ (for no longer than $20 \mathrm{~d}$ ) before use in the study. The patties were thawed at $4^{\circ} \mathrm{C}$ for $24 \mathrm{~h}$ then heated in a $650 \mathrm{~W}$ microwave oven (Panasonic NN-6558; Matsushita Electrical Industrial Co. Ltd, Osaka, Japan) for $1 \mathrm{~min}$ on the 'high' setting before presentation to the participants as part of test breakfasts.

\section{Test breakfasts}

Each of the three breakfast challenges consisted of one sausage patty, a quarter segment of which was presented at the side of the plate (for sensory evaluation). The remainder of the sausage patty was presented between two slices of toasted English muffin (Tip Top; George Weston Foods, Chatswood, NSW, Australia) spread with $10 \mathrm{~g}$ low-fat margarine (Becel Light; Unilever Australasia Ltd, Epping, NSW, Australia). In addition, $20 \mathrm{~g}$ tomato sauce (Heinz Big Red; Heinz Watties Australasia, Hawthorn, VIC, Australia), $50 \mathrm{~g}$ mushrooms fried in $5 \mathrm{~g}$ low-fat margarine and a cup of decaffeinated tea (Tetley Australia, South Yarra, VIC, Australia) with $20 \mathrm{~g}$ skimmed milk (Skinny Milk; National Foods Ltd, Melbourne, VIC, Australia) were provided. All breakfasts were adjusted to an equal weight by altering the amount of water in the tea in order to remove the potential for the weight and volume of the test meal to influence satiety (Blundell \& Stubbs, 1998).

\section{Nutrient analysis}

The fat and protein content of each of the cooked sausage patty variants and a composite sample consisting of the remainder of the breakfast ingredients (as presented to the participants) was determined directly in triplicate using standard methods. Fat content was measured by Soxhlet ether extraction (Association of Official Analytical Chemists, 1995). Protein was measured by Kjeldahl $\mathrm{N}$ distillation (Association of Official Analytical Chemists, 1995), using a semi-micro Kjeldahl autoanalyser (Gerhardt GmbH \& Co., 53119 Bonn, Germany) and an N conversion factor of 6.25. Available carbohydrate was estimated using nutritional information sourced from suppliers and nutrient analysis software (FoodWorks Professional Edition, version 3.01.472; Xyris Software, Brisbane, Australia).
The energy content of the patties was calculated using standard energy factors (Garrow \& James, 1998). The total macronutrients contributed by the test breakfasts was calculated by summing the mean value for the appropriate patty with the mean value for the composite sample of the remainder of the breakfast ingredients.

\section{Satiety ratings}

Perceptions of satiety were rated using a $150 \mathrm{~mm}$ structured graphical scale marked with a far-left anchor of 'extremely hungry' followed by anchors $25 \mathrm{~mm}$ apart of 'hungry', 'semi-hungry', 'no particular feeling', 'semi-satisfied', 'satisfied' and 'extremely satisfied' (Holt et al. 1995). The participants were asked to mark a position anywhere along the scale that matched their perception of satiety. The participants' ratings were converted to a numerical score based on the distance in $\mathrm{mm}$ from the far-left anchor of the scale. Incremental satiety scores for each breakfast were calculated by subtracting each participant's fasting satiety score from their satiety score at each postbreakfast time point. Incremental satiety responses for each breakfast were calculated as each participant's area under the curve of incremental satiety score $v$. time from start of breakfast using above-baseline trapezoidal calculation (Wolever et al. 1991).

\section{Sensory acceptability ratings}

Acceptability of the sausage patty segments was rated using a $150 \mathrm{~mm}$ structured graphical hedonic scale marked with a far-left anchor of 'extremely unacceptable' followed by anchors $25 \mathrm{~mm}$ apart of 'very unacceptable', 'unacceptable', 'neither acceptable or unacceptable', 'acceptable', 'very acceptable' and 'extremely acceptable' (Holt et al. 1995; Clark \& Johnson, 2002). Panellists rated the overall appearance of the patty segment before tasting, then rated its flavour, texture (in mouth) and general acceptability. The participants were asked to mark a position anywhere along the scale that matched their perception and participants' ratings were converted to a numerical score based on the distance in $\mathrm{mm}$ from the far-left anchor of the scale. The participants were also provided with the opportunity to make general written comments regarding the sausage patties.

\section{Food intake}

All food and drink consumed on the day of each test breakfast and the following day was weighed (using electronic food scales) or volume measured (using measuring cups and a graduated measuring jug) and recorded. From these data, fat and energy intakes were determined from the food records using nutrient analysis software (FoodWorks, version 2.1; Xyris Software, Brisbane, Australia).

\section{Test-day procedure}

The participants attended the university in a fasted state, on three mornings, usually the same day of the week on three consecutive weeks, having been instructed to refrain from 
eating and drinking after 22.00 hours, the evening before. The participants were seated in individual booths in a purpose-built sensory evaluation room illuminated by Sylvanis Luxline Plus fluorescent lighting (Osram Australia Pty Ltd, Melbourne, VIC, Australia), where they rated their perception of satiety. The participants then rated the sensory acceptability of the quarter segment of a sausage patty presented as part of the breakfast. They were then required to consume the remainder of the breakfast in its entirety within $15 \mathrm{~min}$. At $15 \mathrm{~min}$ after the start of the test breakfast, the participants again rated their perception of satiety. The participants were then free to leave the university, but were requested to refrain from eating and drinking for $4.5 \mathrm{~h}$ after consuming the breakfast. At 45, 105, 165, 225 and 285 min after the start of breakfast, the participants were requested to rate their perception of satiety.

Before leaving the university, on completion of the first test breakfast, each participant was provided with a set of electronic scales, measuring cups and a graduated measuring jug, then trained by researchers in the accurate measurement of the weight (to an accuracy of $1 \mathrm{~g}$ ) or volume of food and drink. The participants were also provided with a food diary that contained detailed instructions on how to record, in as much detail as possible, every item that they ate or drank, how the item was prepared and its accurately measured weight or volume. The participants were instructed to consume food and drink ad libitum after the $4.5 \mathrm{~h}$ fast following each test breakfast, and to record all food and drink consumed for the remainder of the test day and the following day. After completion, researchers discussed each food record with the participant, reviewed the information and discussed any unclear or missing information with the participant.

\section{Statistical analysis}

All statistical analyses were performed using SPSS (version 10) for WINDOWS (SPSS Inc., Chicago, IL, USA). General linear model repeated-measures ANOVA with general linear model contrast (simple) was used to examine the within-subject effect of sausage patty type on patty acceptability measures, perceptions of satiety at individual time points, satiety response, and fat and energy intakes on the test day, the following day and the test and following day combined. In all analyses $P<0.05$ was considered significant. The participants' level of dietary restraint was not considered in the analysis. One participant did not complete the 'appearance' rating scale for the INP or the 'general acceptability' rating for the FFP and eighteen participants provided comments on the FFP, twenty-one on the INP and twenty on the LKP.

\section{Ethical considerations}

Deakin University ethics committee approved the study. All participants received written information about the study before giving their informed consent.

\section{Results \\ Test foods and breakfasts}

The macronutrient composition of the sausage patties is shown in Table 2. Reformulation of the sausage patties with inulin or lupin-kernel fibre resulted in a reduction in the fat content and hence energy density of the patties whilst the protein and available carbohydrate contents remained relatively similar in all three patties. In comparison with the FFP, the INP was $56 \%$ lower in fat and $36 \%$ lower in energy density, whilst the LKP was $59 \%$ lower in fat and $39 \%$ lower in energy density. Both the INP and the LKP fulfilled the requirements for 'reduced fat' and 'reduced energy' claims according to the Code of Practice Nutrient Claims in Food Labels and in Advertisements, effective in Australia (National Food Authority, 1995). The differences in fat and energy levels of the patties were reflected in those of the complete breakfasts (Table 3). In comparison with the FFP breakfast, the INP

Table 2. Macronutrient composition of sausage patties used in test breakfasts (Mean values)

\begin{tabular}{lccccc}
\hline & $\begin{array}{c}\text { Weight of } \\
\text { patty }(n 3)(\mathrm{g})\end{array}$ & $\begin{array}{c}\text { Fat }(n 3) \\
(\mathrm{g} / 100 \mathrm{~g})\end{array}$ & $\begin{array}{c}\text { Protein }(n 3) \\
(\mathrm{g} / 100 \mathrm{~g})\end{array}$ & $\begin{array}{c}\text { Available carbohydrate* } \\
(\mathrm{g} / 100 \mathrm{~g})\end{array}$ & $\begin{array}{c}\text { Energy } \\
(\mathrm{kJ} / 100 \mathrm{~g})\end{array}$ \\
\hline Full-fat patty & 96.7 & $14 \cdot 2$ & 17.2 & 4.3 & 874 \\
Inulin patty & 103.3 & 6.3 & 16.2 & 4.1 & 562 \\
Lupin-kernel-fibre patty & 108.7 & 5.8 & 15.6 & 3.9 & 531 \\
\hline
\end{tabular}

\footnotetext{
* Indirect analysis.
}

† By calculation.

Table 3. Total macronutrients contributed by the test breakfasts (g)

\begin{tabular}{lccccc}
\hline & Weight of breakfast (g) & Fat (g) & Protein (g) & Available carbohydrate* $^{*}(\mathrm{~g})$ & Energy† (kJ) \\
\hline Full-fat-patty breakfast & 406 & $20 \cdot 7$ & $27 \cdot 2$ & 34.4 & 1786 \\
Inulin-patty breakfast & 406 & 13.3 & 27.3 & 34.4 & 1514 \\
Lupin-kernel-fibre-patty breakfast & 406 & 13.0 & 27.5 & 34.4 & 1506 \\
\hline
\end{tabular}

* Indirect analysis.

† By calculation. 
breakfast was $36 \%$ lower in fat and $15 \%$ lower in energy density, whilst the LKP breakfast was $37 \%$ lower in fat and $17 \%$ lower in energy density.

\section{Sensory acceptability ratings}

The mean scores for the general acceptability of all three sausage patties were greater than 7.5 (Table 4), therefore being on average rated more favourably than 'neither acceptable or not acceptable' by the participants. ANOVA of rating of general acceptability showed a trend towards a main effect of sausage patty type $(F(2,31) 2.576 ; P=0.084)$ with the INP rated lower than the FFP (degrees of freedom (df) $31 ; P=0 \cdot 039$ ). ANOVA of rating of flavour also showed a trend towards a main effect of sausage patty type $(F(2,31) 2.918 ; P=0.061)$ with the LKP rated lower than the FFP (df 32; $P=0.023)$. No other differences in the acceptability ratings were found between the three patties.

In their general written comments on the sausage patties (Table 5), the participants noted blandness in all patties, though less so for the FFP. Comments relating to dryness were more frequent for the INP and the LKP than the FFP. Comments related to light, insipid colour were noted in the both the FFP and the LKP, but more so in the latter.

\section{Satiety ratings}

Incremental post-breakfast satiety scores for the three breakfasts are shown in Fig. 1. ANOVA of incremental satiety score showed a strong trend towards a main effect of breakfast type $(F(2,32) 3 \cdot 139 ; P=0.050)$ at $105 \mathrm{~min}$ from the start of breakfast when the incremental satiety score for the LKP breakfast was higher than that for both the FFP breakfast (df 32; $P=0.017$ ) and the INP breakfast (df $32 ; P=0 \cdot 040$ ). At $165 \mathrm{~min}$ from the start of breakfast, a trend towards a main effect of breakfast type $(F(2,32)$ $2.615 ; P=0.081)$ was observed, the incremental satiety score of the LKP breakfast being higher than that for the FFP breakfast (df $32 ; P=0.031$ ). At $285 \mathrm{~min}$ from the start of breakfast, a significant main effect of breakfast type $(F(2,32) 3.535 ; P=0.035)$ was observed, the incremental satiety score of the LKP breakfast being higher

Table 4. Sensory acceptability ratings of full-fat, inulin and lupinkernel-fibre sausage patties ( $n$ 33)

(Mean values and standard errors of the mean)

\begin{tabular}{|c|c|c|c|c|c|c|}
\hline \multirow[b]{3}{*}{$\begin{array}{l}\text { Overall } \\
\text { appearance }\end{array}$} & \multicolumn{6}{|c|}{ Acceptability rating } \\
\hline & \multicolumn{2}{|c|}{ Full-fat patty } & \multicolumn{2}{|c|}{ Inulin patty } & \multicolumn{2}{|c|}{$\begin{array}{l}\text { Lupin-ker- } \\
\text { nel- } \\
\text { fibre patty }\end{array}$} \\
\hline & 9.3 & 0.44 & 8.8 & 0.48 & $9 \cdot 2$ & 0.3 \\
\hline Flavour & $10 \cdot 4^{a}$ & 0.29 & $10 \cdot 0$ & 0.31 & $9 \cdot 5^{\mathrm{b}}$ & 0.3 \\
\hline Texture & $10 \cdot 1$ & 0.37 & 9.7 & 0.37 & 9.4 & 0.41 \\
\hline $\begin{array}{l}\text { General } \\
\text { acceptability }\end{array}$ & $10 \cdot 2^{a}$ & 0.31 & $9 \cdot 5^{\mathrm{b}}$ & 0.37 & 9.5 & 0.35 \\
\hline
\end{tabular}

${ }^{a, b}$ Mean values within a row with unlike superscript letters are significantly different $(P<0.05)$.
Table 5. Frequency of participants' comments on full-fat, inulin and lupin-kernel-fibre sausage patties that were common to more than $10 \%$ of respondents

\begin{tabular}{|c|c|c|}
\hline $\begin{array}{l}\text { Sausage } \\
\text { patty type }\end{array}$ & Type of comment & $\begin{array}{l}\text { Frequency of } \\
\text { comment type } \\
\text { (\% of } \\
\text { respondents) }\end{array}$ \\
\hline Full-fat & $\begin{array}{l}\text { Looks insipid, looks unappetising } \\
\text { Bland flavour } \\
\text { Texture too soft, no texture }\end{array}$ & $\begin{array}{l}11 \\
11 \\
11\end{array}$ \\
\hline Inulin & $\begin{array}{l}\text { Dry, fibrous, gristly, stringy, tough } \\
\text { Prefer thinner, too thick } \\
\text { Bland taste } \\
\text { Fine texture, no texture, soft texture }\end{array}$ & $\begin{array}{l}24 \\
19 \\
14 \\
14\end{array}$ \\
\hline \multirow[t]{7}{*}{$\begin{array}{l}\text { Lupin- } \\
\text { kernel- } \\
\text { fibre }\end{array}$} & $\begin{array}{l}\text { Colour too light, insipid, looks } \\
\text { unappetising, looks plain and } \\
\text { uninteresting }\end{array}$ & 20 \\
\hline & Bland taste, tasteless & 15 \\
\hline & $\begin{array}{l}\text { Smooth texture, prefer more rough } \\
\text { and chunky texture, prefer } \\
\text { more meaty texture }\end{array}$ & 15 \\
\hline & Dry & 10 \\
\hline & Firm texture and bite, chewy, coarse & 10 \\
\hline & Not too fatty, less oily & 10 \\
\hline & Too thick & 10 \\
\hline
\end{tabular}

than that for the FFP breakfast (df $32 ; P=0.022$ ) and the INP breakfast (df 32; $P=0 \cdot 048$ ). There were no differences in the incremental satiety scores $(P>0.05)$ for the INP breakfast compared with the FFP breakfast at any time point.

ANOVA of satiety response showed a significant main effect of breakfast type $(F(2,32) 3.978 ; P=0.024)$. The satiety response for the LKP breakfast was higher than that of the FFP breakfast (df $32 ; P=0.016)$ and the INP breakfast (df 32; $P=0 \cdot 010$ ) (Fig. 2). No significant difference was found between satiety responses for the INP breakfast compared with the FFP breakfast.

The mean unadjusted baseline (fasting) satiety scores were $(\mathrm{cm})$ : FFP breakfast, $5 \cdot 3$ (range 2.5-13.3); INP breakfast, 5.1 (range 2.0-12.5); LKP breakfast, 4.5 (range $1 \cdot 2-10 \cdot 1)$. The lack of heavy clustering at the farleft anchor (unadjusted score of $0.0 \mathrm{~cm}$ ) of the line-scale suggests that 'floor effects' were unlikely to have biased responses.

\section{Food intakes}

ANOVA of total fat intake on the test day showed a significant main effect of breakfast type $(F(2,32)$ 4.022; $P=0.023$ ), being significantly lower on the day of consumption of the INP (df 32; $P=0.035$ ) and LKP (df 32; $P=0.013$ ) breakfasts than on the day of consumption of the FFP breakfast (Fig. 3). Total energy intake on the test day showed a trend towards a main effect of breakfast type $(F(2,32) 2.612 ; P=0.081)$, being lower on the day of consumption of the INP breakfast (df $32 ; P=0.039)$ and showing a strong trend towards being lower on the day of consumption of the LKP breakfast (df $32 ; P=0.053$ ) than on the day of consumption of the FFP breakfast 


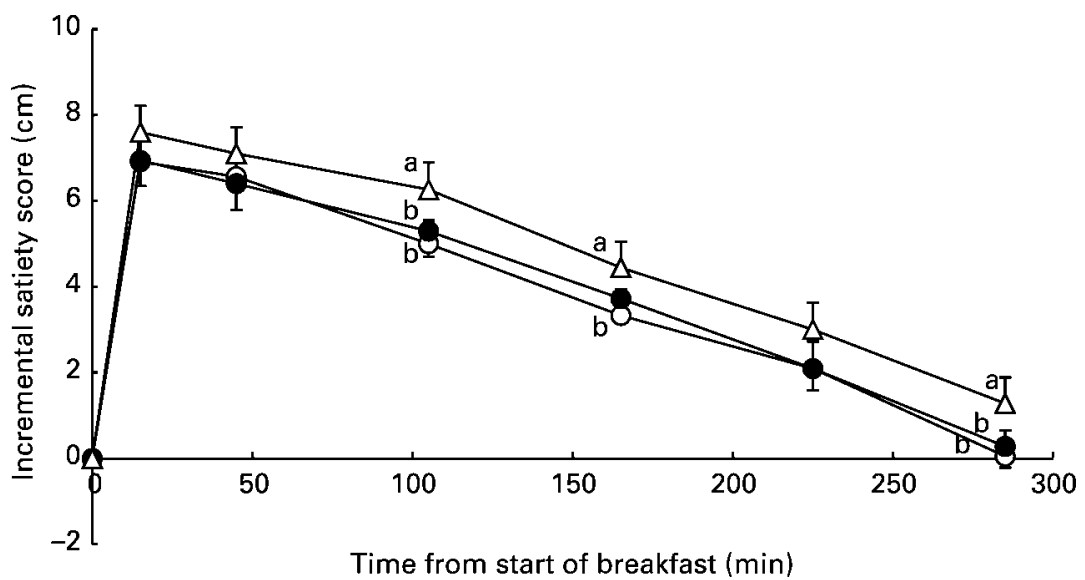

Fig. 1. Incremental satiety ratings after consumption of full-fat-patty $(O)$, inulin-patty $(\bullet)$ and lupin-kernel-fibre-patty $(\Delta)$ breakfasts. Values are means, with standard errors of the mean represented by vertical bars $(n 33) .{ }^{\text {a,b }}$ Mean values at individual time points with unlike letters are significantly different $(P<0.05)$.

(Fig. 4). There was no significant effect of breakfast type on total fat or energy intake on the day following the test day or on the test day and the following day combined. No adverse effects were reported from consuming any of the breakfasts.

\section{Discussion}

The present study provides the first reported experimental evidence of satiating effects in human volunteers of inulin and lupin-kernel fibre when used as fat replacers, though lupin consumption has previously been reported to reduce appetite in pigs (Gannon et al. 1996) and anecdotally in human consumers (Longnecker, 1999). In the present study, each breakfast variant had equal mass, appeared similar in volume, and had equal protein and available carbohydrate content. The experimental design of the study therefore removed some possible confounding variables, in particular serving size and protein content; variables that are known to be correlated with satiety

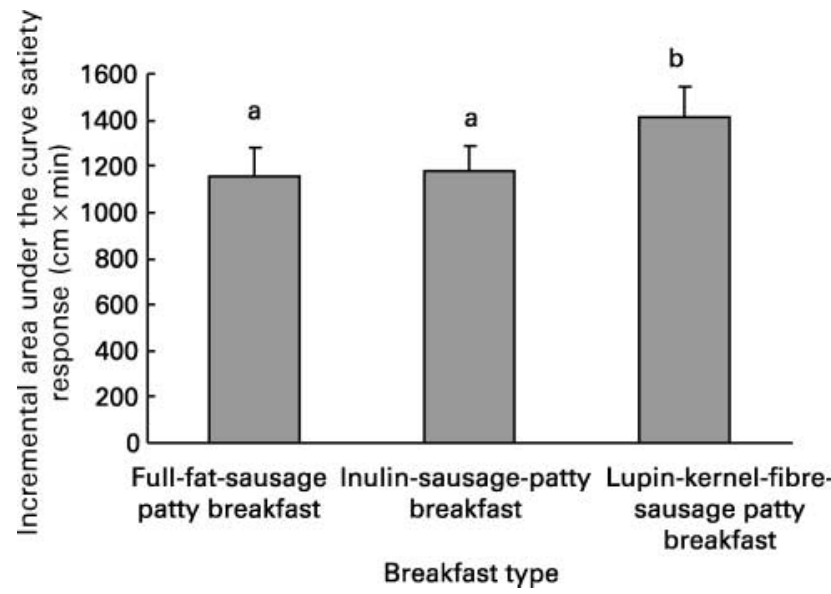

Fig. 2. Satiety response (incremental area under the curve) for fullfat-patty, inulin-patty and lupin-kernel-fibre-patty breakfasts. Values are means, with standard errors of the mean represented by vertical bars $(n 33)$. ${ }^{a, b}$ Mean values with unlike letters are significantly different $(P<0.05)$.
(Holt et al. 1995). This provided greater confidence that any observed effects on satiety were related to the fatreplacement strategies used.

The LKP breakfast produced greater effects on perceptions of satiety than both the FFP breakfast and the INP breakfast, despite the LKP breakfast providing less energy than the FFP breakfast and similar energy to the INP breakfast. The INP breakfast provided less energy than the FFP breakfast but did not differ in its effect on perceptions of satiety, suggesting that inulin did impact on early post-meal satiety, joule for joule, though not to the magnitude of lupin-kernel fibre.

Lupin-kernel fibre, though primarily insoluble, has chemical similarities to pectin, a soluble fibre (Evans \& Cheung, 1993), and has high water-binding and viscosity properties compared with other insoluble dietary fibres under in vitro conditions simulating the human stomach and duodenum (CM Turnbull, AL Baxter and SK Johnson, unpublished results). The observed effect of lupin-kernel fibre on early post-ingestion perceptions of satiety could therefore be a result of water uptake and increased viscosity in the stomach and small intestine leading to

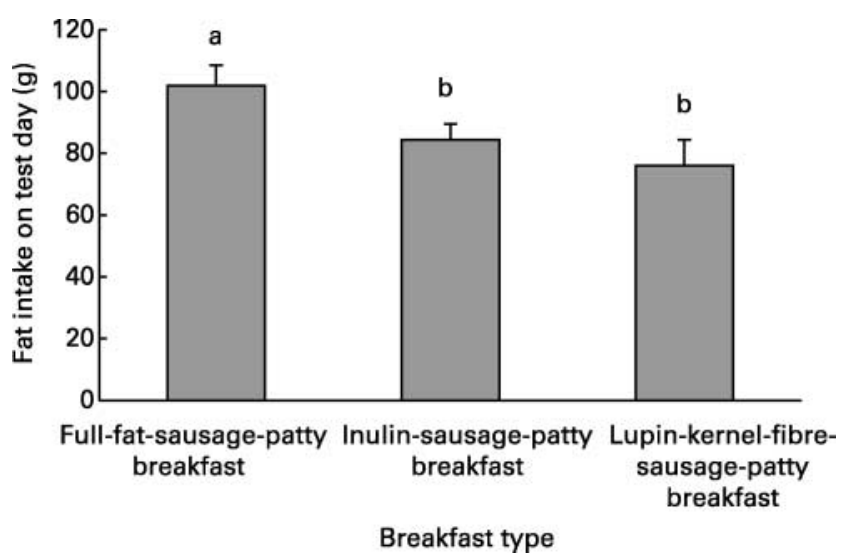

Fig. 3. Test-day total fat intake. Values are means, with standard errors of the mean represented by vertical bars ( $n 33)$. ${ }^{a, b}$ Mean values with unlike letters are significantly different $(P<0.05)$. 


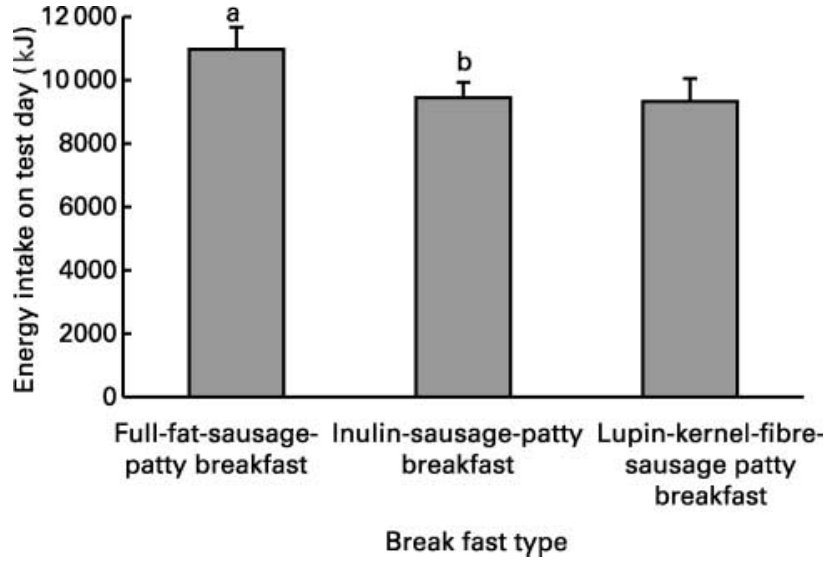

Fig. 4. Test-day total energy intake. Values are means, with standard errors of the mean represented by vertical bars $(n 33){ }^{a, b}$ Mean values with unlike letters are significantly different $(P<0.05)$.

slower gastric emptying and slower digestion and thus an increase in post-ingestion, pre-absorptive satiety signals (Blundell \& Stubbs, 1999). The satiety mechanism of lupin-kernel fibre we have proposed is therefore similar to that previously described for soluble viscous dietary fibres such as guar gum, and pectin (Di Lorenzo et al. 1988; French \& Read, 1994; Pasman et al. 1997; Tiwary et al. 1997; Kovacs et al. 2002). Inulin, unlike lupinkernel fibre, is soluble and may therefore have also exerted any early post-meal satiety effects through a similar mechanism to that reported for guar gum and pectin.

In the present study total food intake, including the experimental breakfast, was used to examine whether the participants fully compensated for the lower intake of fat and energy from the INP and the LKP breakfasts; an approach previously used by Lawton et al. (1993). The lower energy intake on the test day by the participants consuming the LKP and INP breakfasts compared with the FFP breakfast suggests that full compensation for the lower energy content of the INP and LKP breakfasts did not occur. Although the use of food records has limitations in terms of their accuracy for the assessment of ad libitum food intake, the results of the present study suggested the possibility that the daily replacement of fat by inulin or lupin-kernel fibre may be of benefit in reducing long-term fat and energy intake. Further studies using alternative approaches for food intake measurement such as an ad libitum lunch from a controlled buffet and longer-term food selection from food boxes supplied by researchers are required to confirm the effects on fat and energy intake found in the present study. Inulin is highly fermentable by human colon bacteria leading to the production of short-chain fatty acids (Cherbut, 2002). Late post-absorptive satiety triggers related to the absorption and metabolism of these short-chain fatty acids (Blundell \& Stubbs, 1999) may help explain why inulin, though not influencing early post-meal perceptions of satiety, did appear to influence longer-term food intake. It appears that inulin and lupin-kernel fibre may impact on satiety through different physiological mechanisms, which highlights the opportunity for investigating the possibility of synergistic blends of these two fibres in further studies.
Lupin-kernel fibre and inulin have the potential to provide consumers with fat-reduced foods with elevated satiating effects (joule for joule) compared with the full-fat counterparts; a property of fat replacers that has recently be identified as important in the literature (Tremblay et al. 2002). Similar effects on satiety as determined in the present study have been found for synthetic sucrose polyester fat replacers. Energy intake after a meal in which fat is replaced by sucrose polyester has generally resulted in incomplete compensation in the short term (Roberts et al. 1998). The effect of the use of plant-derived indigestible carbohydrate fat replacers on the satiating power of food products has rarely been reported in the literature, though indirect evidence suggests that fat replacement with dietary fibre should increase a food's satiating power joule for joule. For instance, the dietary fibre content of food correlates positively with effects on satiety, whereas fat content correlates negatively (Holt et al. 1995) and the simple addition of dietary fibre to foods is generally considered to have a positive effect on satiety (Burley \& Blundell, 1990; Levine \& Billington, 1994). The effect on satiety of breakfasts consisting of sausage in which fat was replaced by cellulose has been investigated (Reddy et al. 1996) with the conclusion that the use of cellulose did not affect perceptions of satiety, but the low energy of the test breakfast was not compensated for on the test day or on the following day.

Maintaining high palatability of fat-reduced foods using low-energy fat replacers appears important when aiming to reduce overall dietary energy intake. This is because if fat replacers can impart to fat-reduced food the same desirable sensory characteristics as the full-fat product, individuals might compensate in terms of subsequent energy intake as if the fat-reduced product were actually a full-fat product (Roberts et al. 1998). In the present study, though some of the acceptability scores of the fat-replaced patties were lower than those for the FFP, the mean general acceptability rating of all three sausage patty variants was well above the mid-point of the rating scale, suggesting that consumers did not have an aversion to any of the products. In contrast to the present study, Devereux et al. (2003) found no significant difference in the overall acceptability of low-fat beef sausage containing inulin compared with the full-fat counterpart.

The reduction in flavour of meat products, that is known to occur when their fat content is reduced (Homer et al. 2000), was apparent in the present study in which the replacement of fat by lupin-kernel fibre gave a reduced flavour acceptability score. In addition, a higher frequency of comments referring to the bland nature of the INP and LKP compared with the FFP was recorded. The lower flavour ratings of the INP and LKP may be related to a reduction in fat-soluble flavour compounds contributed by the beef dripping and, in the case of the LKP, atypical flavours contributed by residual non-dietary fibre components of the lupin-kernel-fibre ingredient. The use of additional flavours in the fat-reduced products could be used to improve sensory acceptability (Yackinous \& Guinard, 2000). The participants made comments referring to dryness of the fat-reduced patties, but not the full-fat product, suggesting that the use of the fat replacers in the present study did not 
fully mimic the desirable 'juicy' mouthfeel properties typical of full-fat products. It will be important to improve the 'juiciness' of the fat-reduced patties in future studies since this parameter is known to be directly related to the overall palatability of low-fat sausage-type products (Yang et al. 2001).

It has been demonstrated that there is an inverse relationship between the satiety effect (joule for joule) of a diverse range of foods and their palatability (Holt et al. 1995). The results of the present study demonstrate that the use of inulin and lupin-kernel fibre as fat replacers has the potential to break this paradigm, by providing palatable but also highly satiating low-energy-dense food products.

The present study demonstrates the potential of inulin and lupin-kernel fibre as effective fat replacers in the formulation of palatable foods with high satiating powers that may be of value in diets designed to reduce longterm energy and fat intake. Nevertheless, since compensation for lower energy intake might occur with repeated fat replacement, longer-term studies are required to determine the efficacy of inulin and lupin-kernel fibre for the dietary control of body-weight maintenance and reduction. In the present study, subjects were of a wide range of age and BMI. Highly satiating foods may not be of value to the elderly who may wish to maximise energy intake whereas highly satiating but palatable foods may be of particular value to the obese to limit energy intake. The elderly and obese may respond uniquely to fat replacement in foods; therefore specific studies investigating the palatability and satiating properties of inulin and lupin-kernel fibre are required in these at-risk consumer groups.

\section{Acknowledgements}

We thank Mandurah Australia Pty Ltd for the donation of the inulin, Australasian Natural Ingredients Pty Ltd and Food Science Australia for the donation of lupin-kernel fibre and the participants for taking part. This research was supported by a grant from Deakin University.

\section{References}

Association of Official Analytical Chemists (1995) Official Methods of Analysis, 16th ed., Washington, DC: Association of Official Analytical Chemists.

Astrup A, Grunwald GK, Melanson EL, Saris WHM \& Hill JO (2000) The role of low-fat diets in body weight control: a meta-analysis of ad libitum dietary intervention studies. Int $J$ Obes Relat Metab Disord 24, 1545-1552.

Astrup A, Toubro S, Raben A \& Skov AR (1997) The role of lowfat diets and fat substitutes in body weight management: what have we learned from clinical studies? J Am Diet Assoc 97, S82-S87.

Blundell JE, Burley V, Cotton JR \& Lawton CL (1993) Dietary fat and the control of energy intake: evaluating the effects of fat on meal size and post meal satiety. Am J Clin Nutr 57, S772-S778.

Blundell JE \& Rogers PJ (1991) Hunger, hedonics and the control of satiation and satiety. In Chemical Senses: Appetite and Nutrition, pp. 127-148 [MI Friedman, MG Tordoff and MR Kare, editors]. New York: Marcel Dekker Inc.

Blundell JE \& Stubbs RJ (1998) Diet composition and the control of food intake in humans. In Handbook of Obesity, pp. 243-278 [GA Bray, C Bouchard and WPT James, editors]. New York: Marcel Dekker Inc.

Blundell JE \& Stubbs RJ (1999) High and low carbohydrate and fat intakes: limits imposed by appetite and palatability and their implications for energy balance. Eur J Clin Nutr 53, S148-S165.

Bray GA \& Popkin BM (1998) Dietary fat intake does affect obesity. Am J Clin Nutr 68, 1157-1173.

Burley VJ \& Blundell JE (1990) Action of dietary fibre on the satiety cascade. In Dietary Fibre: Chemistry, Physiology, and Health Effects, pp. 227-246 [D Kritchevsky, C Bonfield and JW Anderson, editors]. New York: Plenum Press.

Cherbut $C$ (2002) Inulin and oligofructose in the dietary fibre concept. Br J Nutr 87, S159-S162.

Clark RL \& Johnson SK (2002) Sensory acceptability of foods with added lupin (Lupinus angustifolius) kernel fiber using pre-set criteria. J Food Sci 67, 356-362.

Devereux HM, Jones GP, McCormack L \& Hunter WC (2003) Consumer acceptability of low fat foods containing inulin and oligofructose. J Food Sci 68, 1850-1854.

Di Lorenzo C, Williams CM, Hajina F \& Valenzuela JE (1988) Pectins delays gastric emptying and increases satiety in obese subjects. Gastroenterology 95, 1211-1215.

Drewnowski A (1998) Energy density, palatability, and satiety: implications for weight control. Nutr Rev 56, 347-353.

Evans AJ \& Cheung PCK (1993) The carbohydrate composition of cotyledons and hulls of cultivars of Lupinus angustifolius from Western Australia. J Sci Food Agric 61, 189-194.

Franck A (2002) Technological functionality of inulin and oligofructose. Br J Nutr 87, S287-S291.

French SJ \& Read NW (1994) Effect of guar gum on hunger and satiety after meals of differing fat content: relationship with gastric emptying. Am J Clin Nutr 59, 87-91.

Gannon NJ, Nason RG, Mullan BP, van Barneveld RJ, King RH \& Dunshea FR (1996) Lupin based diets increase digesta retention in growing pigs. Proc Nutr Soc Aust 20, 54.

Garrow JS \& James WPT (1998) Human Nutrition and Dietetics, 9th ed., London: Churchill Livingstone.

Glanz K, Basil M, Maibach E, Goldberg J \& Snyder D (1998) Why Americans eat what they do: taste, nutrition, cost, convenience and weight control concerns as influences on food composition. J Am Diet Assoc 98, 1118-1126.

Holt SHA, Brand Miller JC, Petocz P \& Farmakalidis E (1995) A satiety index of common foods. Eur J Clin Nutr 49, 675-690.

Homer DB, Matthews KR \& Warkup CC (2000) The acceptability of low fat sausages. Nutr Food Sci 30, 67-72.

Johnson SK \& Gray DM (1993) Ingredients derived from lupin strong potential for a range of dietary fibre applications. In International Food Ingredients, no. 5: pp. 18-23, Cmp Information Ltd London.

Kovacs EMR, Westerterp-Plantenga MS, Saris WHM, Melanson KJ, Goossens I, Geurten P \& Brouns F (2002) The effect of guar gum addition to a semisolid meal on appetite related to blood glucose, in dieting men. Eur J Clin Nutr 56, 771-778.

Lawton CL, Burley VJ, Wales JK \& Blundell JE (1993) Dietary fat and appetite control in obese subjects: weak effects on satiation and satiety. Int J Obes Relat Metab Disord 17, 409-416.

Levine AS \& Billington CJ (1994) Dietary fiber: does it affect food intake and body weight? In Appetite and Body Weight Regulation: Sugar, Fat and Macronutrient Substitutes, pp. 191-200 [JD Fernstrom and GD Miller, editors]. Boca Raton, FL: CRC Press Inc.

Longnecker N (1999) Passion for Pulses. Nedlands, Australia: University of Western Australia Press.

National Food Authority (1995) Code of Practice - Nutrient 
Claims in Food Labels and in Advertisements. Canberra: Australian Government Publishing Service.

Niness KR (1999) Inulin and oligofructose: what are they? J Nutr 129, S1402-S1406.

Orafti (1997) Raftiline (doc B1-60* 2/97). Aandorenstraat, Belgium: Orafti.

Pasman WJ, Saris WHM, Wauters MAJ \& WesterterpPlantenga MS (1997) Effect of one week of fibre supplementation on hunger and satiety ratings and energy intake. Appetite $\mathbf{2 9}$, $77-87$.

Raben A, Agerholm-Larsen L, Flint A, Holst JJ \& Astrup A (2003) Meals with similar energy densities but rich in protein, fat, carbohydrate, or alcohol have different effects on energy expenditure and substrate metabolism but not on appetite and energy intake. Am J Clin Nutr 77, 91-100.

Reddy S, Kilcast D, Thane C \& Church N (1996) Effect of highenergy and reduced-energy breakfasts comprising fat-substituted foods on appetite, satiety and subsequent nutrient intake. Nutr Food Sci 5, 30-36.

Roberts SB, Pi-Sunyer FX, Dreher M, et al. (1998) Physiology of fat replacement and reduction: effects of dietary fat and fat substitutes on energy regulation. Nutr Rev 56, S29-S49.

Rolls BJ, Hetherington M \& Burley VJ (1988) The specificity of satiety: the influence of different macronutrient contents on development of satiety. Physiol Behav 43, 145-153.

Rolls BJ, Kim-Harris S, Fischman MW, Foltin RW, Moran TH \& Stoner SA (1994) Satiety after preloads with different amounts of fat and carbohydrate: implications for obesity. Am J Clin Nutr 60, 476-487.

Tiwary CM, Ward JA \& Jackson BA (1997) Effect of pectin on satiety in healthy US army adults. $J$ Am Coll Nutr 16, 423-428.

Tremblay A, Dumesnil JG \& Depres J-P (2002) Diet, satiety and obesity treatment. Br J Nutr 88, 213-214.

Walker KZ, Birkett A, Lu ZX, Jones G, O’Dea L \& Muir JG (1997) Development of a simulated Australian diet for adults which may have use as a research tool. Aust J Nutr Diet 54, 190-197.

Willet WC (1998a) Dietary fat and obesity: an unconvincing relation. Am J Clin Nutr 68, 1149-1150.

Willet WC (1998b) Is dietary fat a major determinant of body fat? Am J Clin Nutr 67, 556S-562S.

Wolever TMS, Jenkins DJA, Jenkins AL \& Josse RG (1991) The glycemic index: methodology and clinical implications. Am J Clin Nutr 54, 846-854.

Yackinous C \& Guinard J-S (2000) Flavour manipulation can enhance the impression of fat in some foods. J Food Sci $\mathbf{6 5}$, 909-914.

Yang A, Keeton JT, Beiken SL \& Trout GR (2001) Evaluation of some binders and fat substitutes in low-fat frankfurters. J Food Sci 66, 1039-1046.

Yeomans MR, Gray RW, Mitchell C \& True S (1997) Independent effects of palatability and within-meal pauses on intake and appetite ratings in human volunteers. Appetite 29, 61-76. 